\title{
Clinical utility gene card for: familial polycythaemia vera
}

\author{
Kais Hussein ${ }^{\star, 1}$, Galit Granot ${ }^{2}$, Ofer Shpilberg ${ }^{2}$ and Hans Kreipe ${ }^{1}$ \\ European Journal of Human Genetics (2013) 21, doi:10.1038/ejhg.2012.216; published online 3 October 2012
}

\section{DISEASE CHARACTERISTICS}

1.1 Name of the disease (synonyms)

Polycythaemia vera (PV; polycythaemia rubra vera, Osler-Vasquezsyndrome), entity of Philadelphia chromosome-negative myeloproliferative neoplasms (MPN).

\subsection{OMIM\# of the disease}

263300 .

1.3 Name of the analysed genes or DNA/chromosome segments Janus kinase 2 (JAK2)/chromosome segment 9p24.

Other genes that can be associated with familial PV:

Ten-eleven translocation 2 (TET2)/4q24.

Egl nine homologue 1 (C. elegans) (EGLN1, synonym HIF prolyl hydroxylase 2, PHD2)/1q42.

\subsection{OMIM\# of the gene(s)}

147796 (JAK2).

Other genes that can be associated with familial PV:

612839 (TET2).

606425 (EGLN1).

\subsection{Mutational spectrum}

Somatic JAK2 exon 14 G1849T/V617F (80-100\% of all familial and sporadic PV patients). ${ }^{1-4}$

Multiple somatic JAK2 exon 12 (non-V617F) mutations $(<10 \%$ of familial and sporadic PV patients). ${ }^{5-8}$

Germ-line JAK2 polymorphism rs10974944. ${ }^{9-12}$

Multiple somatic TET2 exons 3-12 mutations (10-15\% of V617Fpositive familial and sporadic PV patients). ${ }^{12-14}$

Germ-line EGLN1 G471C/G147H (JAK2 V617F-positive familial PV case). ${ }^{15}$

Recurrent somatic cytogenetic aberrations in $20-30 \%$ of familial PV and sporadic PV $(+8,+9, \operatorname{del}(9 \mathrm{p}), \operatorname{del}(13 \mathrm{q})$ and $\operatorname{del}(20 \mathrm{q})) \cdot{ }^{16,17}$

\subsection{Analytical methods}

Sequencing of peripheral blood or bone marrow leukocytes (DNA and/or RNA/cDNA).

Restriction analysis for JAK2 G1849T mutation: the mutation abolishes a BsaX I restriction endonuclease recognition site. Required mutation analysis: JAK2 gene. Optional mutation analysis: TET2, EGLN1.

Cytogenetics.

\subsection{Analytical validation}

Bidirectional sequencing, double measurements.

Control samples: mutated cell lines (JAK2 V617F $+/+$ HEL, MB-02, MUTZ-8 and UKE-1, JAK2 V617F+/- SET- $2^{18}$ ), mutated patient sample, unmutated patient sample or unmutated cell lines (eg, HL60).

\subsection{Estimated frequency of the disease}

The exact population prevalence and incidence for familial PV is not known but likely $<1 / 100000$ (sporadic PV: population prevalence 25/100 000; incidence: $0.7-2.6 / 100000) .{ }^{19,20}$

1.9 If applicable, prevalence in the ethnic group of investigated person

The exact prevalence in different ethnic groups is not known, but likely $<1: 100000$ for familial PV. In principle, individuals from any ethnic group can develop familial and sporadic PV. An ethnic association is known for Jewish descent, particularly Ashkenazi (5.8\% PV cases versus 3\% in a reference population in France). ${ }^{21}$

\subsection{Diagnostic setting}

\begin{tabular}{lcc}
\hline & Yes & No \\
\hline A. (Differential) diagnostics & $\bigotimes$ & $\square$ \\
B. Predictive Testing & $\square$ & $\square$ \\
C. Risk assessment in relatives & $\bigotimes$ & $\square$ \\
D. Prenatal & $\square$ & $\square$
\end{tabular}

\section{Comment:}

Diagnosis of familial and sporadic PV requires JAK2 mutation analysis. ${ }^{16}$

Prenatal testing is not indicated in familial PV (JAK2 V617F is a somatic mutation that occurs with disease manifestation after birth, and detection of non-V617F JAK2 germ-line polymorphisms or germ-line EGLN1 mutations have no consequence during pregnancy). Prenatal JAK2 V617F PV is extremely rare and is not associated with familial MPN. ${ }^{22}$

${ }^{1}$ Institute of Pathology, Hannover Medical School, Hannover, Germany; ${ }^{2}$ Felsenstein Medical Research Center, Beilinson Hospital, Sackler School of Medicine, Tel Aviv University, Petah Tikva, Israel

*Correspondence: Dr K Hussein, Institute of Pathology, Hannover Medical School, Carl-Neuberg Street 1, 30625 Hannover, Germany. Tel: + 495115324501 ; Fax: + 4951153 25799; E-mail: Hussein.Kais@mh-hannover.de 


\section{TEST CHARACTERISTICS}

\begin{tabular}{|c|c|c|c|c|}
\hline & \multicolumn{2}{|c|}{ Genotype or disease } & \multirow{2}{*}{$\begin{array}{l}\text { A: True positive } \\
\text { B: False positive }\end{array}$} & \multirow{2}{*}{$\begin{array}{l}\text { C: False negative } \\
\text { D: True negative }\end{array}$} \\
\hline & Present & Absent & & \\
\hline \multicolumn{5}{|l|}{ Test } \\
\hline Positive & $A$ & B & $\begin{array}{l}\text { Sensitivity: } \\
\text { Specificity: }\end{array}$ & $\begin{array}{l}A /(A+C) \\
D /(D+B)\end{array}$ \\
\hline Negative & C & D & $\begin{array}{l}\text { Positive predictive value: } \\
\text { Negative predictive value: }\end{array}$ & $\begin{array}{l}A /(A+B) \\
D /(C+D)\end{array}$ \\
\hline
\end{tabular}

2.1 Analytical sensitivity

(proportion of positive tests if the genotype is present)

$>99 \%$ (false-negative $<1 \%$ ).

2.2 Analytical specificity

(proportion of negative tests if the genotype is not present)

$>99 \%$ (false-positive rate $<1 \%$ ).

\subsection{Clinical sensitivity}

(proportion of positive tests if the disease is present)

The clinical sensitivity is undetermined but likely $>50 \%$ of cases with PV and positive family history are positive for JAK2 V617F.

\subsection{Clinical specificity}

(proportion of negative tests if the disease is not present)

The clinical specificity is undetermined but likely $>99 \%$ of cases with no PV are negative for JAK2 V617F.

\subsection{Positive clinical predictive value}

(life-time risk of developing the disease if the test is positive)

The general risk to develop a familial PV is increased if JAK2

V617F is detected, but JAK2 V617F can be associated with other MPN entities. The risk to develop a familial PV is undetermined if EGLN1 is found to be mutated. ${ }^{15}$ TET2 and cytogenetic aberrations alone are too unspecific (occur also in other myeloid neoplasms) for determination of a positive clinical predictive value.

JAK2 polymorphism rs10974944 predisposes to the development of $\mathrm{PV}$ and other entities of $\mathrm{MPN}^{9-12}$ but is not a genetic indicator of familial PV/MPN. ${ }^{12}$

\subsection{Negative clinical predictive value} (probability of not developing the disease if the test is negative) The negative predictive value is undetermined but likely low (JAK2 mutation-negative $\mathrm{PV}<10 \%$ ).

\section{CLINICAL UTILITY}

3.1 (Differential) diagnosis: The tested person is clinically affected (To be answered if in 1.10 ' $\mathrm{A}$ ' was marked)

The diagnosis of familial PV requires at least one other PV patient in the family or any other non-PV MPN (referred to as familial MPN). ${ }^{23}$ The familial predisposition is consistent with autosomal dominant inheritance with incomplete penetrance. A positive family anamnesis of an effected PV patient increases the risk 3-7-fold of
MPN manifestation in other family members in general but not necessarily a PV. ${ }^{23,24}$

Familial PV cases are genetically and phenotypically indistinguishable from sporadic PV. The disease onset is similar in familial and sporadic cases (median age at diagnosis $\sim 60$ years; in general juvenile PV cases are rare). ${ }^{19,24,25}$ However, the second generation patients are often younger than those of the first generation. ${ }^{20}$ Prenatal PV is extremely rare and has been described as a sporadic event. $^{22}$

Consider screening those with:

- True erythrocytosis.

- No identifiable secondary cause.

- Young patients.

- Thromboembolic complications.

- Positive family history.

Diagnosis of familial and sporadic PV according to the 2008 classification of the World Health Organization ${ }^{19}$ requires both major criteria and one minor criterion or, major criterion 1 and two of three minor criteria.

Major criteria:

1. Increased red blood cell parameters: haemoglobin $>185 \mathrm{~g} / \mathrm{l}$ (men)/ $>165 \mathrm{~g} / \mathrm{l}$ (women) or haemoglobin >170 g/l (men)/>150g/l (women) if associated with a documented and sustained increase of at least $20 \mathrm{~g} / \mathrm{l}$ from an individual's baseline value that cannot be attributed to correction of iron deficiency or haemoglobin/haematocrit $>99$ th percentile of methodspecific reference range for age, sex and altitude of residence or elevated red blood cell mass $>25 \%$ above mean normal predicted value.

2. JAK2 exon 14 V617F mutation or other functionally similar JAK2 exon 12 mutations.

\section{Minor criteria:}

1. Bone marrow histology shows prominent trilineage proliferation of mature erythropoiesis, granulopoiesis and megakaryopoiesis. Megakaryocytes characteristically show pleomorphic cytoplasmic diameters, normal or hyperlobulated nuclei, loose clustered and paratrabecular distribution.

2. Serum erythropoietin levels below the reference range for normal.

3. Endogenous erythroid colony formation in vitro.

\section{Differential diagnosis:}

Detection of JAK2 and TET2 mutations allows the molecular discrimination of neoplastic proliferation in terms of MPN/PV from primary and reactive erythrocythosis. Non-neoplastic primary familal erythrocytosis typically exhibit mutations of the oxygen pathway and has no elevated risk of blastic transformation. ${ }^{19,26}$ EGLN1 mutation is usually found in familial non-PV/nonneoplastic erythrocytosis but can also be present in familial JAK2 V617F PV. ${ }^{15}$

JAK2 and TET2 mutations are not specific for PV, neither in general nor for sporadic and familial cases. These mutations can be detected in other MPN (50-60\% of essential thrombocythemia and primary myelofibrosis cases are JAK2 V617F-positive), myelodysplastic syndromes (particularly TET2 mutations), MPN, unclassifiable and myelodysplastic/myeloproliferative neoplasms (both JAK2 and TET2 mutations). ${ }^{1-14}$ 


\subsubsection{Can a diagnosis be made other than through a genetic test?}

$\begin{array}{ll}\text { No } & \square \text { (continue with 3.1.4) } \\ \text { Yes } \square & \\ \text { Clinically } & \square \\ \text { Imaging } & \square \\ \text { Endoscopy } & \square \\ \text { Biochemistry } & \square \\ \text { Electrophysiology } & \square \\ \text { Other } & \square \\ & \text { Peripheral blood analysis: evaluation of haematological } \\ & \text { (red blood cell) parameters and EPO levels. } \\ & \text { Bone morrow histology. } \\ & \text { Endogenous erythroid colony formation assay. } \\ & \text { Anamnesis (the clinical presentation is mainly unspeci- } \\ & \text { fic, eg B-symptoms and abdominal pain due to spleno- } \\ & \text { megaly or thromboembolic complication-associated } \\ & \text { symptoms). }\end{array}$

3.1.2 Describe the burden of alternative diagnostic methods to the patient

Low: blood collection is required not only for mutation analyses but also for evaluation of red cell parameters and EPO level.

Low/medium: bone marrow biopsy; infiltration of the periosteum with local anaesthetic can relieve the pain of a bone marrow biopsy.

Low/medium: physical examinations and additional examinations (eg, sonography/radiology) for the evaluation of splenomegaly, hepatomegaly and/or thromboembolic complications.

3.1.3 How is the cost effectiveness of alternative diagnostic methods to be judged?

Analysis of red blood cell parameters and EPO levels: low costs, low/ medium sensitivity and specificity.

Physical and additional examinations: depending on the examination medium to high costs, low/medium sensitivity and specificity.

3.1.4 Will disease management be influenced by the result of a genetic test?

No $\square$

Yes $\otimes$

Therapy Phlebotomy, anticoagulation, myelosuppressive agents. JAK2

inhibitors are under development.

Prognosis Good prognosis, 10 years survival $>80 \% .{ }^{23}$

Possible complications: thrombosis, thromboembolism,

haemorrhage.

Disease progression (late phase of disease): post-PV

myelofibrosis with increased splenomegaly, anaemia and

B-symptoms, myelodysplasia and/or acute myeloid

leukaemia. ${ }^{19}$

Management Provide information for the patient, control of disease status.

3.2 Predictive setting: The tested person is clinically unaffected but carries an increased risk based on family history

(To be answered if in 1.10 'B' was marked)

3.2.1 Will the result of a genetic test influence lifestyle and prevention? No (independent of the positive/negative result of the test), because the result of the genetic test on its own has no implication on lifestyle and prevention.
3.2.2 Which options in view of lifestyle and prevention does a person at-risk have if no genetic test has been done (please describe)?

Regular follow-up examinations.

3.3 Genetic risk assessment in family members of a diseased person (To be answered if in 1.10 ' $\mathrm{C}$ ' was marked)

3.3.1 Does the result of a genetic test resolve the genetic situation in that family?

A JAK2 polymorphism can be associated with an elevated risk to develop a JAK2 V617F-positive MPN in affected families ${ }^{9}$ but the presence of the polymorphism alone does not necessarily result in disease manifestation. Therefore, there is no established genetic test for genetic risk assessment.

3.3.2 Can a genetic test in the index patient save genetic or other tests in family members?

No, because JAK2 V617F and TET2 mutations are somatic alterations and the disease is transmitted with an incomplete penetrance. ${ }^{23}$

3.3.3 Does a positive genetic test result in the index patient enable a predictive test in a family member?

No, somatic JAK2 V617F can be associated with another MPN entity.

3.4 Prenatal diagnosis

(To be answered if in 1.10 'D' was marked)

3.4.1 Does a positive genetic test result in the index patient enable a prenatal diagnosis?

Not applicable.

\section{IF APPLICABLE, FURTHER CONSEQUENCES OF TESTING}

Advantage of genetic testing:

(1) Clear-cut discrimination between neoplastic and non-neoplastic erythrocytosis.

(2) Quantification of JAK2 mutant alleles for monitoring therapy and disease status.

(3) In case of bone marrow transplantation after post-PV myelofibrosis, JAK2 V617F and other non-germ-line mutations can be used as molecular markers for minimal residual disease.

\section{CONFLICT OF INTEREST}

The authors declare no conflict of interest.

\section{ACKNOWLEDGEMENTS}

This work was supported by EuroGentest, an EU-FP6 supported NoE, contract number 512148 (EuroGentest Unit 3: 'Clinical Genetics, Community Genetics and Public Health', Workpackage 3.2).

1 James C, Ugo V, Le Couédic JP et al: A unique clonal JAK2 mutation leading to constitutive signalling causes polycythaemia vera. Nature 2005; 434: 1144-1148.

2 Hussein K, Bock O, Theophile K et al: JAK2(V617F) allele burden discriminates essential thrombocythemia from a subset of prefibrotic-stage primary myelofibrosis. Exp Hematol 2009; 37: 1186-1193.

3 Bellanné-Chantelot C, Chaumarel I, Labopin M et al: Genetic and clinical implications of the Val617Phe JAK2 mutation in 72 families with myeloproliferative disorders. Blood 2006; 108: 346-352.

4 Hussein K, Bock O, Ballmaier M et al: Familial polycythemia vera with non-germline JAK2(V617F) mutation sparing the abnormal and clonal granulopoiesis. Leukemia 2007; 21: 2566-2568. 
5 Scott LM, Tong W, Levine RL et al: JAK2 exon 12 mutations in polycythemia vera and idiopathic erythrocytosis. N Engl J Med 2007; 356: 459-468.

$6 \mathrm{Ma}$ W, Kantarjian $\mathrm{H}$, Zhang X et al: Mutation profile of JAK2 transcripts in patients with chronic myeloproliferative neoplasias. Mol Diagn 2009; 11: 49-53.

7 Percy MJ, Scott LM, Erber WN et al: The frequency of JAK2 exon 12 mutations in idiopathic erythrocytosis patients with low serum erythropoietin levels. Haematologica 2007; 92: 1607-1614.

8 Pietra D, Li S, Brisci A et al: Somatic mutations of JAK2 exon 12 in patients with JAK2 (V617F)-negative myeloproliferative disorders. Blood 2008; 111: 1686-1689.

9 Kilpivaara O, Mukherjee S, Schram AM et al: A germline JAK2 SNP is associated with predisposition to the development of JAK2(V617F)-positive myeloproliferative neoplasms. Nat Genet 2009; 41: 455-459.

10 Jones AV, Chase A, Silver RT et al: JAK2 haplotype is a major risk factor for the development of myeloproliferative neoplasms. Nat Genet 2009; 41: 446-449.

11 Olcaydu D, Harutyunyan A, Jager R et al: A common JAK2 haplotype confers susceptibility to myeloproliferative neoplasms. Nat Genet 2009; 41: 450-454.

12 Olcaydu D, Rumi E, Harutyunyan A et al: The role of the JAK2 GGCC haplotype and the TET2 gene in familial myeloproliferative neoplasms. Haematologica 2011; 96: 367-374.

13 Saint-Martin C, Leroy G, Delhommeau F et al: Analysis of the ten-eleven translocation 2 (TET2) gene in familial myeloproliferative neoplasms. Blood 2009; 114: 1628-1632.

14 Tefferi A, Pardanani A, Lim KH et al: TET2 mutations and their clinical correlates in polycythemia vera, essential thrombocythemia and myelofibrosis. Leukemia 2009; 23 905-911.

15 Albiero E, Ruggeri M, Fortuna S et al: Analysis of the oxygen sensing pathway genes in familial chronic myeloproliferative neoplasms and identification of a novel EGLN1 germ-line mutation. Br J Haematol 2011; 153: 405-408.

16 Bacher U, Schnittger S, Kern W, Weiss T, Haferlach T, Haferlach C: Distribution of cytogenetic abnormalities in myelodysplastic syndromes, Philadelphia negative myeloproliferative neoplasms, and the overlap MDS/MPN category. Ann Hematol 2009; 88: 1207-1213.

17 Kralovics R, Stockton DW, Prchal JT: Clonal hematopoiesis in familial polycythemia vera suggests the involvement of multiple mutational events in the early pathogenesis of the disease. Blood 2003; 102: 3793-3796.

18 Quentmeier H, MacLeod RA, Zaborski M, Drexler HG: JAK2 V617F tyrosine kinase mutation in cell lines derived from myeloproliferative disorders. Leukemia 2006; 20 . 471-476.

19 Swerdlow SH, Campo E, Harris NL et al. (eds): WHO classification of tumours of hematopoietic and lymphoid tissues. Lyon: IARC press, 2008, vol 4.

20 Rumi E, Passamonti F, Della Porta MG et al: Familial chronic myeloproliferative disorders: clinical phenotype and evidence of disease anticipation. J Clin Oncol 2007; 25: $5630-5635$

21 Anderson LA, Duncombe AS, Hughes M, Mills ME, Wilson JC, McMullin MF: Environmental, lifestyle, and familial/ethnic factors associated with myeloproliferative neoplasms. Am J Hematol 2012; 87: 175-182.

22 Kelly K, McMahon C, Langabeer S, Eliwan H, O‘Marcaigh A, Smith OP: Congenital JAK2V617F polycythemia vera: where does the genotype-phenotype diversity end? Blood 2008; 112: 4356-4357.

23 Rumi E: Familial chronic myeloproliferative disorders: the state of the art. Hematol Oncol 2008; 26: 131-138.

24 Landgren O, Goldin LR, Kristinsson SY, Helgadottir EA, Samuelsson J, Björkholm M: Increased risks of polycythemia vera, essential thrombocythemia, and myelofibrosis among 24,577 first-degree relatives of 11039 patients with myeloproliferative neoplasms in Sweden. Blood 2008; 112: 2199-2204.

25 Cario H, McMullin MF, Pahl HL: Clinical and hematological presentation of children and adolescents with polycythemia vera. Ann Hematol 2009; 88: 713-719.

26 Hussein K, Percy M, McMullin MF: Clinical utility gene card for: Familial erythrocytosis. Eur J Hum Genet 2012; 20: e1-e4. 